\title{
Secretion compounds from Brevibacillus sp. SUT47 promote spore propagation of Acaulospora tuberculata colonizing maize roots (Zea mays L. cultivar Suwan 5)
}

\author{
Sutee Kiddee $^{\mathrm{a}}$, Watcharin Yuttavanichakul ${ }^{\mathrm{a}}$, Nantakorn Boonkerd ${ }^{\mathrm{a}}$, Neung Teaumroong ${ }^{\mathrm{a}}$, \\ Katsuharu Saito ${ }^{\mathrm{b}}$, Panlada Tittabutr ${ }^{\mathrm{a}, *}$ \\ a School of Biotechnology, Institute of Agricultural Technology, Suranaree University of Technology, \\ Nakhon Ratchasima 30000 Thailand \\ b School vof Science and Technology, Institute of Agriculture, Shinshu University, Minamiminowa, \\ Nagano 399-4598 Japan
}

*Corresponding author, e-mail: panlada@sut.ac.th

Received 18 May 2020

Accepted 18 Jul 2020

\begin{abstract}
The substrate-based production system has been widely applied for farm arbuscular mycorrhizal fungi (AMF) inoculum production. Plant growth promoting rhizobacterium (PGPR), Brevibacillus sp. SUT47 has been discovered to promote AMF spore production when co-inoculating on maize roots. However, the application of whole cell bacteria may cause the adverse outcome with contamination of bacterial cells in AMF inoculum. In order to avoid the bacterial cell contamination, we attempted to develop a new methodology using the bacterial secretion compounds as an optional technique to promote AMF spore production in maize roots. Secretion compounds of strain SUT47 were concentrated by freeze-drying and co-inoculated with the spores of Acaulospora tuberculata on maize seedling. The results showed that the bacterial secretion compounds promoted AMF spore production. The highest number of spores was produced when $360 \mathrm{mg}$ of concentrated secretion compounds were applied. In contrast, the significant reduction of spore number was found when the secretion compounds at the concentration higher than $360 \mathrm{mg}$ were applied. These results indicate the production of AMF spore was responded to concentration of bacterial secretion compounds which possibly contain an effective substance to promote AMF spore propagation.
\end{abstract}

KEYWORDS: Acaulospora tuberculata, Brevibacillus sp., secretion compounds, spore propagation

\section{INTRODUCTION}

Arbuscular mycorrhizal fungi (AMF) have been widely distributed to terrestrial plants and have a potential role to improve plant nutrients [1]. AMF can be used as a biofertilizer to increase plant yield in eco-agricultural system [2]. The need of AMF inoculants has continuously increased due to their potential support on plant growth through water and mineral nutrient acquisition that is particularly suitable for the situation of growing plant under climate changes. Nevertheless, the bottle neck of AMF application is the insufficient supply of AMF inoculants due to difficult, laborious, and timeconsuming process of AMF inoculant production. The most convenience with low cost AMF propagation technique is the substrate-based system, which is normally used for farmers in developing countries. However, the propagation rate is usually low.

Previously, the mycorrhization helper bacteria (MHB) which are clearly selective of the fungal species and adapted to live in the close vicinity of the mycorrhizal fungus and their function were reported to be involved in mycorrhiza formation [3-5]. MHB can promote the AMF infection in the different stages during tripartite of bacterium-fungus-plant interaction. For example, at pre-infection phase including spore germination and hyphal growth was enhanced by MHB $[6,7]$. The exudate of MHB is one of the factors capable of stimulating fungal spore germination. Many researchers reported that some rhizospheric bacteria and their culture filtrates were able to stimulate the spore germination and hyphal growth of Glomus mosseae, G. fistulosum, and G. versiforme [8-11]. Not only MHB but also some of plant growth promoting rhizobacteria (PGPR) were reported to promote biomass of AMF [12]. However, few reports have been focused on the application of these bacteria to promote the propagation of AMF spores for inoculant production. 
Previously, our team reported an effective PGPR, Brevibacillus sp. SUT47 as a biofertilizer for forage corn (Zea mays L.) [13], and this strain also played the role on the enhancement of the colonization and spore production of Acaulospora tuberculata in maize roots (Zea mays L. cultivar Suwan 5) under the substrate-based system [14]. However, the drawback of this technique when applied for AMF inoculum production is the presence of strain SUT47 cells contaminated in AMF inoculum, and it may not be appropriate if the high purity of AMF spores is needed. To solve this problem, the aim of this present study is to develop the new methodology using the cell free-culture of strain SUT47 (the secretion compounds) to increase the spore propagation of $A$. tuberculata, which has been widely used as a biofertilizer [15-18] for a better quality of AMF inoculant production.

\section{MATERIALS AND METHODS}

\section{Preparation of bacterial cells and secretion compounds}

The starter culture of Brevibacillus sp. SUT47 was prepared in Luria-Bertani (LB) broth. Then, $0.1 \%$ $(\mathrm{v} / \mathrm{v})$ of the fresh culture $\left(\mathrm{OD}_{600}=1.0\right.$; approximate cell number at $10^{8} \mathrm{CFU} / \mathrm{ml}$ ) was inoculated into $1000 \mathrm{ml} \mathrm{LB}$ broth and incubated on the shaker at $28^{\circ} \mathrm{C}, 150 \mathrm{rpm}$ for $20 \mathrm{~h}$ before separating the bacterial cells and the supernatant (secretion compounds) using centrifugation. The culture at $20 \mathrm{~h}$ after inoculation was in the late log phase of growth, which is the duration that cells may secrete and accumulate the highest amount of metabolites in the medium while the cells are still active. The secretion compounds were filtered twice using Nalgene filter funnel (Thermo Scientific) combined with nylon membrane with pore size of $0.45 \mu \mathrm{m}$ and $0.2 \mu \mathrm{m}$, respectively, to get rid of all bacterial cells. Then, the cell free-culture was subjected to freeze-drying process to concentrate the secretion compounds by taking out $100 \mathrm{ml}$ of the culture and transferring to 500-ml CHRIST freeze-drying flasks. The program of freeze-drying machine (Christ/Gamma2-16 LSCplu, Germany) was set at the shelf temperature of $-70^{\circ} \mathrm{C}$ with vacuum at $0.110 \mathrm{mbar}$ for $28 \mathrm{~h}$. The crude powder of the secretion compounds was collected into dry tubes and stored at $-80^{\circ} \mathrm{C}$ until use. The fresh LB broth medium was also freezedried and used as control while the bacterial cells were washed twice and dissolved in normal saline $(\mathrm{NaCl} 0.85 \%(\mathrm{w} / \mathrm{v}))$ by adjusting the bacterial cell density equal to $10^{8}$ cells $/ \mathrm{ml}$ and used for further experiment.

\section{AMF inoculant production under substrate- based system}

The AMF inoculant production test was conducted using pot culture technique under the controlled greenhouse condition at Suranaree University of Technology ( $14^{\circ} 52^{\prime} 21.4^{\prime \prime}$, E: $\left.102^{\circ} 1^{\prime} 20.2^{\prime \prime}\right)$ during Jan-Apr, 2018. Maize (Zea mays L. cultivar Suwan 5) was used as a host plant. The seeds were surface sterilized and germinated in a sterilized paper towel. After 3 days, 1 seedling was transplanted into the pot $\left(\begin{array}{ll}1 & 1\end{array}\right)$ containing the mixture by volume of sterilized vermiculite:sand (1:1). Seedling was inoculated with 100 spores of A. tuberculata (FJ687415) (School of Biotechnology, Suranaree University of Technology, Thailand) per pot. One$\mathrm{ml}$ containing $10^{8}$ cells of SUT47 was co-inoculated once with AMF as a positive control treatment while different concentrations $(90,180,270,360$, and $540 \mathrm{mg} / \mathrm{ml} /$ plant) of SUT47 secretion compounds were applied to determine the effect on promoting AMF spore propagation. The same amount of freeze-dried LB broth at each concentration was included in the experiment as a control. Each treatment was performed with 6 replications compared with AMF-inoculated plant. Plants were grown under the greenhouse with the light $14 \mathrm{~h} / 10 \mathrm{~h}$ and temperatures at $30 \pm 4^{\circ} \mathrm{C} / 28 \pm 4^{\circ} \mathrm{C}$ day/night cycle. Plant nutrients of $400 \mathrm{ml}$ were exactly irrigated every 3 days with a half strength of modified Hoagland solution with $100 \mu \mathrm{M}$ Pi [18].

\section{Data collection}

Post inoculation at 3 months, 3 replications of each treatment were harvested to determine plant biomass, chlorophyll content, and histological analysis. The chlorophyll contents were measured using a spectrophotometer (SPAD502 Plus) on the third and fourth leaves (from top). The plant shoots and roots were harvested and dried at $70^{\circ} \mathrm{C}$ for $48 \mathrm{~h}$ [19]. Mycorrhizal infection was observed using the trypan blue staining method revealed by Phillips and Hayman [20] and the percentage of colonization was observed using grid-line intersect method [21]. The remaining plants were further dried by stop watering for 1 month before collecting AMF spores.

\section{AMF spore counting and statistical analysis}

The AMF spores were extracted from the substrate in each pot using the wet-sieving method followed by sucrose gradient centrifugation $[22,23]$. The 

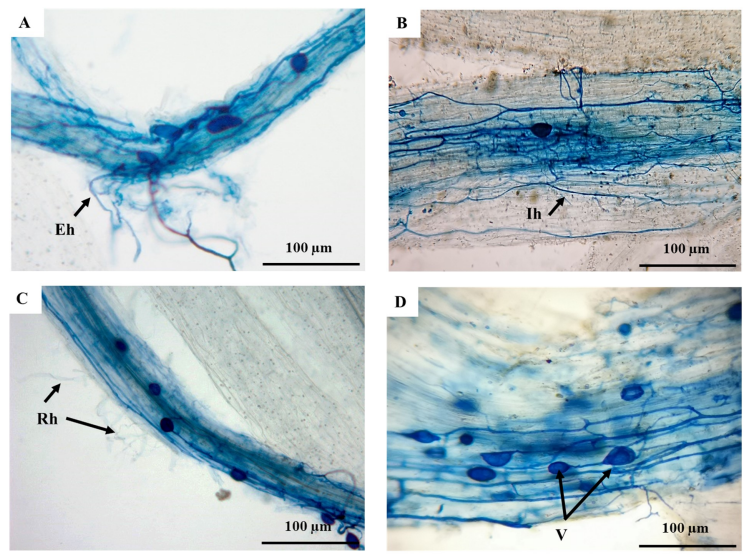

Fig. 1 Trypan blue staining of the fungal colonization in maize roots by A. tuberculata. Trypan blue staining of the roots was used to visualize fungal structures at $90 \mathrm{dpi}$ under compound microscope: (A) extracellular hyphae, Eh; (B) intracellular hyphae, Ih; (C) maize root hair, Rh; and (D) vesicle, $\mathrm{V}$.

statistical analyses were performed using SPSS 16.0 statistical software package (SPSS Inc., Chicago, IL, USA). Data analyses were carried out using Tukey's honest significance test with $p<0.05$ significance level to determine the significance of differences between the treatments.

\section{RESULTS}

Plant biomass was determined at 3 months after inoculation, and the data were presented in Table S1. The plant growth according to the shoot dry weight and root dry weight was not significantly different among the treatments. Plant acquisition of nutrients revealed in root/shoot ratio and the chlorophyll content also showed no significant difference. Thus, there was no direct effect of nutrients from LB broth, secretion compounds as well as the application of whole cell SUT47 on plant growth. The fungal structure and root colonization efficiency were also determined in the maize roots. There was no significant difference in the AMF root colonization efficiency among all treatments (Fig. 1 and Table S1).

Then, the number of AMF spore was determined at 4-month-old plant. The results showed that coinoculation of AMF with the cells of Brevibacillus sp. SUT47 produced the highest number of spore propagation. The number of AMF spores was 1.2 times higher than that of the control (AMF inoculation alone) (Fig. 2). Interestingly, the co-inoculation of AMF with the SUT47 secretion compounds also correlatively increased the number of AMF spores up to

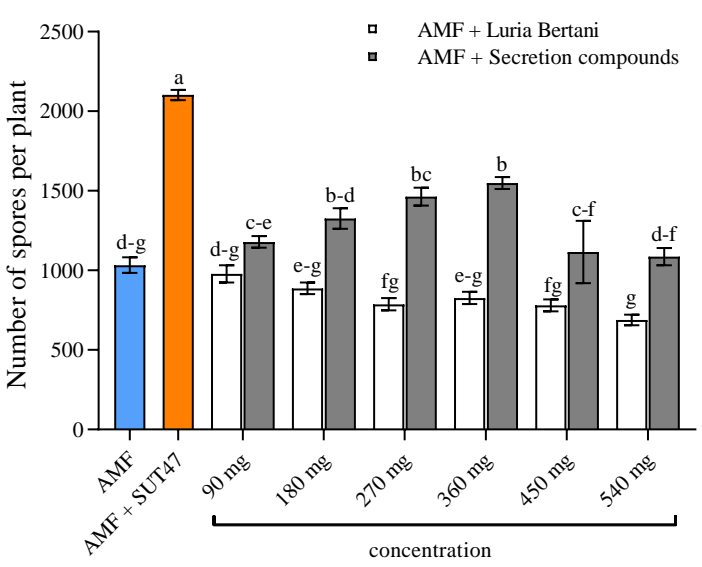

Fig. 2 Number of AMF spore formation at 4 months; inoculated with AMF alone (blue bar), co-inoculated with SUT47 cell (orange bar), and co-inoculated with different concentrations of Luria Bertani medium (white bars) or SUT47 secretion compounds (grey bars). Extra-spore isolated from the substrate mixture of sand: vermiculite (1:1) contained in the pot. Data are reported as averages and standard error of mean (SEM) in triplicate. Same letters above the bars indicate no significant difference among treatments. Statistical analysis was determined using Tukey's HSD test $(p<0.05)$.

a certain concentration of the SUT47 secretion compounds. However, the number of AMF spores was lower than that of co-inoculation using SUT47 cells. Based on the application of secretion compounds, the significant increase of AMF spores was found when applying the secretion compounds at 270 and $360 \mathrm{mg}$ which increased the spore number of $\mathrm{A}$. tuberculata up to 1463 and 1590 spores/plant, respectively. The co-inoculation of AMF with LB medium at different concentrations was also performed, and the result showed that all concentrations of LB medium significantly reduced the number of AMF spores when compared to the plant inoculated with AMF alone. Therefore, the AMF spore propagation may be inhibited by some composition contained in LB medium that may have an effect mainly on spore germination. Nevertheless, some concentrations of SUT47 secretion compounds could significantly increase the number of AMF spores when compared to control. This result revealed the effect of some compounds secreted from SUT47 that can increase the AMF spore propagation. 


\section{DISCUSSION}

In this study, we developed a new technique using the secretion compounds from Brevibacillus sp. SUT47 to promote the spore propagation of $A$. tuberculata. Brevibacillus sp. SUT47 was discovered to promote AM root colonization and spore number of $A$. tuberculata in maize. This bacterium also has an influence on the alteration of some plant defense-related compounds and antioxidative enzyme activities associated with an enhanced maize root colonization by AMF and may result in the increase of the spore production [14]. Therefore, the strain SUT47 has potential to stimulate AMF spore propagation for the purpose of enhancing AMF inoculum production efficiency under substrate-based production system.

In this study, we focused on the activation of AMF spore number produced per plant using the secretion compounds from the strain SUT47 to avoid the contamination of its bacterial cells in the AMF inoculum. It was found that at the specific concentration of secretion compounds of SUT47 in range of $270-360 \mathrm{mg} /$ plant could promote the spore number of $A$. tuberculata (Fig. 2). This result indicates that the secretion compounds of strain SUT47 contain some substances that may interact with plant or interact directly with AMF and activate the propagation of AMF spores. These interactions seem to be dose responses of the specific beneficial compounds. However, too much concentration of those substances could interfere this beneficial interaction. Nevertheless, the deep biochemical experiments are further required to identify the beneficial compounds and their interaction on AMF or plant, and the structure of main active compound is required to be investigated. However, the number of spores produced from maize treated with secretion compounds was still significantly less than that of plant treated with the living cells of strain SUT47. It could be possible that the colonization of living bacterial cells on maize root could benefit continuously secreted beneficial compounds at suitable amount along with plant growth which is probably better than one time treated with concentrated secretion compounds. Moreover, colonization of living cells could have more interactions with plant through several plant hormones produced from bacteria that may require the signaling from plant or $\mathrm{AMF}$ in tripartite interactions and may results in supporting the AMF spore production. Recently, the effective signalling compounds in broth culture of PGPR had potential to be a biostimulant by promoting seed germination and plant growth at early stage [24]. Several PGPR are known to excrete hormones such as IAA as well as cytokinin and gibberellin that can enhance plant growth [25, 26]. However, this study showed that co-inoculation of AMF with SUT47 living cells or their secretion compounds did not affect plant growth. Although SUT47 has been reported to promote the growth of forage corn [13], this strain when applied together with AMF on maize did not promote plant growth [14]. It is likely possible that these beneficial secretion compounds could directly affect AMF sporulation and spore propagation since there is no effect on the AMF colonization (Fig. 2). It has been reported that inoculation of Klebsiella pneumoniae on sea oats (Unicola paniculata) increased spore germination and hastened branching of Glomus deserticoloa [27].

Therefore, this study showed the application of secretion compounds from SUT47 at the optimal concentration to stimulate spore production of A. tuberculata in maize roots. Although the spore number was lower than that of using living cells of SUT47, this technique may be appropriate for high quality AMF inoculant production to avoid the contamination of bacterial cells. However, the preference or the compatibility among plant host, AMF, and bacterial species could be an obstacle when using this technique to produce other species of AMF inoculant. Thus, the finding of specific compounds that commonly activate the colonization and spore production of various AMF species and their behind mechanisms still remains to be further investigated.

\section{Appendix A. Supplementary data}

Supplementary data associated with this article can be found at http://dx.doi.org/10.2306/ scienceasia1513-1874.2020.073

Acknowledgements: This research was supported by The Royal Golden Jubilee (RGJ) Ph.D. Program, The Thailand Research Fund (TRF), and Suranaree University of Technology (SUT).

\section{REFERENCES}

1. de Marins JF, Carrenho R (2017) Arbuscular mycorrhizal fungi and dark septate fungi in plants associated with aquatic environments. Acta Bot Bras 31, 295-308.

2. Berruti A, Lumini E, Balestrini R, Bianciotto V (2016) Arbuscular mycorrhizal fungi as natural biofertilizers: Let's benefit from past successes. Front Microbiol 6, 1-13. 
3. Garbaye J (1994) Helper bacteria: a new dimension to the mycorrhizal symbiosis. New Phytol 128, 197-210.

4. Bowen GD, Theodorou C (1979) Interactions between bacteria and ectomycorrhizal fungi. Soil Biol Biochem 11, 119-126.

5. Deveau A, Labbé J (2016) Mycorrhiza helper bacteria. In: Martin F (ed) Molecular Mycorrhizal Symbiosis, John Wiley \& Sons, pp 437-450.

6. Bowen GD (1994) The ecology of ectomycorrhiza formation and functioning. Plant Soil 159, 61-67.

7. Schrey SD, Schellhammer M, Ecke M, Hampp R, Tarkka MT (2005) Mycorrhiza helper bacterium Streptomyces AcH 505 induces differential gene expression in the ectomycorrhizal fungus Amanita muscaria. New Phytol 168, 205-216.

8. Mosse B (1962) The establishment of vesiculararbuscular mycorrhiza under aseptic conditions. $\mathrm{Mi}$ blao 27, 509-520.

9. Gryndler M, Vosátka M (1996) The response of Glomus fistulosum maize mycorrhiza to treatments with culture fractions from Pseudomonas putida. Mycorrhiza 6, 207-211.

10. Azcon-Aguilar C, Diaz-Rodriguez RM, Barea JM (1986) Effect of soil micro-organisms on spore germination and growth of the vesicular-arbuscular mycorrhizal fungus Glomus mosseae. T Br Mycol Soc 86, 337-340.

11. Mayo K, Davis RE, Motta J (1986) Stimulation of germination of spores of Glomus versiforme by sporeassociated bacteria. Mycologia 78, 426-431.

12. Frey-Klett P, Chavatte M, Clausse ML, Courrier S, Le RC, Raaijmakers J, Garbaye J (2005) Ectomycorrhizal symbiosis affects functional diversity of rhizosphere fluorescent pseudomonads. New Phytol 165, 317-328.

13. Piromyou P, Buranabnyat B, Tantasawat P, Tittabutr P, Boonkerd N, Teaumroog N (2011) Effect of plant growth promoting rhizobacteria (PGPR) inoculation on microbial community structure in rhizosphere of forage corn cultivated in Thailand. Eur J Soil Biol 47, $44-45$.

14. Yuttavanichakul W, Teamtisong K, Teaumroong N, Boonkerd N, Tittabutr P (2018) Brevibacillus sp. promotes maize root colonization by Acaulospora tuberculata and the alteration of associated plant protein responses. J Plant Interact 13, 543-554.

15. Li H, Wang C, Li X, Xiang D (2013) Inoculating maize fields with earthworms (Aporrectodea trapezoides) and an arbuscular mycorrhizal fungus (Acaulospora tuberculata) improves mycorrhizal community structure and increases plant nutrient uptake. Biol Fertil
Soils 49, 1167-1178.

16. Dalli Y, Yahia N, Hadjadj-Aoul S, Bekki A (2019) Effect of the rhizospheric micro-organisms of some Fabaceaes and peat substratum on the growth of carob tree (Ceratonia siliqua L.). J Agric Sci 11, 86-97.

17. Ntengna YF, Tchameni NS, Fokom R, Sameza ML, Minyaka E, Ngonkeu MEL, Nana L, Wakam Etoa FX, et al (2019) Effects of arbuscular mycorrhiza fungi on stimulation of nutrient content and induction of biochemical defense response in Xanthosoma sagittifolium plants against root rot disease caused by Pythium myriotylum. Int $J$ Adv Agric Res 7, 98-107.

18. Djocgoue PF, Simo C, Minyaka E, Tassong SD, Njonzo NS, Taffouo V (2019) Influence of Gigaspora margarita and Acaulospora tuberculata on tolerance to Phytophthora megakarya in Theobroma cacao under plant nursery conditions. Int J Adv Agric Res 7, 21-31.

19. Shipleyl B, Vu T (2002) Matter content in as a measure of parts dry atter concentration plants and their parts. New Phytol 153, 359-364.

20. Phillips J, Hayman D (1970) Improved procedure of clearing roots and staining parasitic and vesicular arbuscular mycorrhizal fungi for rapid assessment of infection. Trans Br Mycol Soc 55, 158-161.

21. Giovannetti M, Mosse B (1980) An evaluation of techniques for measuring vesicular arbuscular mycorrhizal infection in roots. New Phytol 84, 489-500.

22. Jenkins WR (1964) A rapid centrifugal-flotation technique for separating nematodes from soil. $\mathrm{Pl}$ Dis Rep 48, ID 692.

23. Dandan Z, Zhiwei Z (2007) Biodiversity of arbuscular mycorrhizal fungi in the hot-dry valley of the Jinsha River, southwest China. Appl Soil Ecol 37, 118-128.

24. Backer R, Rokem JS, Ilangumaran G, Lamont J, Praslickova D, Ricci E, Smith DL (2018) Plant growth-promoting rhizobacteria: Context, mechanisms of action, and roadmap to commercialization of biostimulants for sustainable agriculture. Front Plant Sci 871, 1-17.

25. Ruzzi M, Aroca R (2015) Plant growth-promoting rhizobacteria act as biostimulants in horticulture. Sci Hortic-Amsterdam 196, 124-134.

26. Govind G, Shailendra SP, Narendra KA, Sunil KS, Vinod S (2015) Plant growth promoting rhizobacteria (PGPR): current and future prospects for development of unstainable agriculture. $J$ Microbial Biochem Technol 7, 96-102.

27. Will ME, Sylvia DM (1990) Interaction of rhizosphere bacteria, fertilizer, and vesicular-arbuscular mycorrhizal fungi with sea oats. Appl Environ Microb 56, 2073-2079. 


\section{Appendix A. Supplementary data}

Table S1 Biomass production of maize Suwan 5 and fungal colonization at 3 months; inoculation with/without Luria Bertani medium and secretion compounds at the different concentrations.

\begin{tabular}{|c|c|c|c|c|c|c|}
\hline \multirow{2}{*}{ Sample } & \multirow{2}{*}{$\begin{array}{l}\text { Concentration } \\
\text { (mg) }\end{array}$} & \multicolumn{4}{|c|}{ Plant biomass } & \multirow{2}{*}{$\begin{array}{c}\text { Fungal } \\
\text { colonization } \\
(\%)\end{array}$} \\
\hline & & $\begin{array}{l}\text { Chlorophyll content } \\
\text { (SPAD units) }\end{array}$ & $\begin{array}{l}\text { Shoot DW } \\
(\mathrm{g})\end{array}$ & $\begin{array}{l}\text { Root DW } \\
\quad(\mathrm{g})\end{array}$ & $\mathrm{R} / \mathrm{S}$ ratio & \\
\hline $\mathrm{AMF}(-)$ & - & $18.64 \pm 2.42$ & $18.91 \pm 1.47$ & $15.52 \pm 0.86$ & $0.74 \pm 0.06$ & - \\
\hline AMF (-) + SUT47 & - & $19.06 \pm 0.73$ & $20.23 \pm 1.34$ & $14.34 \pm 0.51$ & $0.71 \pm 0.04$ & - \\
\hline $\operatorname{AMF}(-)+$ Secretion & 90 & $18.46 \pm 0.50$ & $18.42 \pm 1.47$ & $15.52 \pm 0.94$ & $0.75 \pm 0.01$ & - \\
\hline $\operatorname{AMF}(-)+$ Secretion & 180 & $17.75 \pm 0.72$ & $17.75 \pm 1.04$ & $16.78 \pm 0.17$ & $0.95 \pm 0.07$ & - \\
\hline $\operatorname{AMF}(-)+$ Secretion & 270 & $18.34 \pm 0.78$ & $18.34 \pm 0.56$ & $17.56 \pm 0.99$ & $0.96 \pm 0.08$ & - \\
\hline $\operatorname{AMF}(-)+$ Secretion & 360 & $19.42 \pm 0.79$ & $19.42 \pm 0.50$ & $17.23 \pm 1.60$ & $0.89 \pm 0.10$ & - \\
\hline $\operatorname{AMF}(-)+$ Secretion & 450 & $17.95 \pm 1.32$ & $17.90 \pm 1.30$ & $16.62 \pm 0.76$ & $0.82 \pm 0.02$ & - \\
\hline $\operatorname{AMF}(-)+$ Secretion & 540 & $17.62 \pm 1.24$ & $17.62 \pm 1.27$ & $16.53 \pm 1.42$ & $0.94 \pm 0.09$ & - \\
\hline $\operatorname{AMF}(+)$ & - & $20.83 \pm 0.38$ & $21.38 \pm 0.48$ & $14.60 \pm 0.80$ & $0.68 \pm 0.04$ & 87.00 \\
\hline $\mathrm{AMF}+\mathrm{SUT} 47$ & - & $23.93 \pm 1.52$ & $21.40 \pm 0.61$ & $15.61 \pm 0.63$ & $0.73 \pm 0.05$ & 92.67 \\
\hline AMF + Luria Bertani & 90 & $21.73 \pm 0.28$ & $23.21 \pm 2.81$ & $20.37 \pm 1.11$ & $0.88 \pm 0.05$ & 79.67 \\
\hline AMF + Luria Bertani & 180 & $27.20 \pm 2.77$ & $23.21 \pm 2.81$ & $18.37 \pm 2.27$ & $0.80 \pm 0.08$ & 80.67 \\
\hline AMF + Luria Bertani & 270 & $20.00 \pm 0.65$ & $25.71 \pm 1.90$ & $19.39 \pm 1.28$ & $0.76 \pm 0.05$ & 86.33 \\
\hline AMF + Luria Bertani & 360 & $17.73 \pm 0.68$ & $21.76 \pm 0.25$ & $17.89 \pm 1.23$ & $0.82 \pm 0.08$ & 82.00 \\
\hline AMF + Luria Bertani & 450 & $21.93 \pm 1.60$ & $23.31 \pm 1.82$ & $17.38 \pm 0.69$ & $0.75 \pm 0.05$ & 79.33 \\
\hline AMF + Luria Bertani & 540 & $19.87 \pm 0.75$ & $24.01 \pm 0.44$ & $18.95 \pm 2.52$ & $0.79 \pm 0.01$ & 79.00 \\
\hline $\mathrm{AMF}+$ Secretion & 90 & $21.20 \pm 2.88$ & $25.06 \pm 1.18$ & $15.25 \pm 2.52$ & $0.61 \pm 0.02$ & 81.67 \\
\hline $\mathrm{AMF}+$ Secretion & 180 & $19.60 \pm 2.15$ & $20.81 \pm 0.71$ & $16.52 \pm 1.11$ & $0.79 \pm 0.01$ & 78.00 \\
\hline AMF + Secretion & 270 & $19.33 \pm 0.64$ & $20.55 \pm 1.07$ & $15.63 \pm 2.27$ & $0.75 \pm 0.06$ & 90.67 \\
\hline $\mathrm{AMF}+$ Secretion & 360 & $19.50 \pm 0.57$ & $20.71 \pm 1.01$ & $13.14 \pm 1.28$ & $0.63 \pm 0.06$ & 81.33 \\
\hline $\mathrm{AMF}+$ Secretion & 450 & $19.50 \pm 1.01$ & $20.22 \pm 0.36$ & $15.64 \pm 1.23$ & $0.77 \pm 0.03$ & 81.33 \\
\hline $\mathrm{AMF}+$ Secretion & 540 & $19.36 \pm 0.33$ & $20.27 \pm 1.86$ & $17.34 \pm 0.69$ & $0.86 \pm 0.04$ & 79.67 \\
\hline
\end{tabular}

AMF (-), no AMF inoculation; AMF (+), inoculation with A. tuberculata; + SUT47, inoculation with SUT47 cells; + secretion, inoculation with SUT47 secretion compounds; + Luria Bertani, inoculation with Luria Bertani medium. The number corresponds with specific plant biomass. Data are presented as averages \pm standard error of mean (SEM) from 3 biological replicates. DW indicates plant dry weight (g/plant). 